\section{Investigation of Pneumonic Plague, Madagascar}

\section{Michel Drancourt, Didier Raoult}

Author affiliation: MEPHI, UMR, IRD, Aix-Marseille Université, Marseille, France

DOI: https://doi.org/10.3201/eid2401.170760

To the Editor: In an investigation of a pneumonic plague outbreak in Madagascar, Ramasindrazana et al. reported isolation of Yersinia pestis from 2 patients and seroconversion in 2 additional patients; these data indicated 4 (28.7\%) of 14 diagnosed cases among described cases (1). The risk for overestimation of pneumonic plague contagion was illustrated by an outbreak in the Democratic Republic of the Congo that included cases of leptospirosis (2). In fact, thorough investigations in Uganda indicated that 2 index patients transmitted $Y$. pestis to only 1 caregiver each and none to 23 additional untreated close contacts (3). Another investigation in China showed that 3 index patients exposed 214 contacts during 3-13 days; all contacts were quarantined, and no secondary cases were reported (4). Transmission of $Y$. pestis by respiratory droplets requires face-to-face exposure with a coughing patient, as can occur during funerals by close contact with coughing persons who may have been exposed to the pathogen while visiting or attending the patient before he or she died. Therefore, the threat for plague epidemics fueled by pneumonic plague can be reduced by measures such as isolating patients and wearing a mask when exposure is likely (5).

We propose the hypothesis that only the transmission of $Y$. pestis by ectoparasites, such as lice and fleas, by close contact with infected humans can sustain outbreaks and epidemics. In plague-endemic regions, to support the appropriate management of patients and provide a rapid and accurate microbiological diagnosis, we recommend point of care laboratories, some of which are now operating in a few remote regions of Africa. In addition to direct diagnosis of disease in humans, direct detection of $Y$. pestis at the point-of-care in potential sources and vectors would facilitate understanding of how plague epidemics sustain.

\section{References}

1. Ramasindrazana B, Andrianaivoarimanana V, Rakotondramanga JM, Birdsell DN, Ratsitorahina M, Rajerison M. Pneumonic plague transmission, Moramanga, Madagascar, 2015. Emerg Infect Dis. 2017;23:521-4. http://dx.doi.org/10.3201/eid2303.161406

2. Bertherat E, Mueller MJ, Shako JC, Picardeau M. Discovery of a leptospirosis cluster amidst a pneumonic plague outbreak in a miners' camp in the Democratic Republic of the Congo. Int J Environ Res Public Health. 2014;11:1824-33. http://dx.doi.org/10.3390/ijerph110201824
3. Begier EM, Asiki G, Anywaine Z, Yockey B, Schriefer ME, Aleti P, et al. Pneumonic plague cluster, Uganda, 2004. Emerg Infect Dis. 2006;12:460-7. http://dx.doi.org/10.3201/ eid1203.051051

4. Li YF, Li DB, Shao HS, Li HJ, Han YD. Plague in China 2014 All sporadic case report of pneumonic plague. BMC Infect Dis. 2016;16:85. http://dx.doi.org/10.1186/s12879-016-1403-8

5. Ratsitorahina M, Chanteau S, Rahalison L, Ratsifasoamanana L, Boisier P. Epidemiological and diagnostic aspects of the outbreak of pneumonic plague in Madagascar. Lancet. 2000;355:111-3. http://dx.doi.org/10.1016/S0140-6736(99)05163-6

Address for correspondence: Michel Drancourt, MEPHI, UMR, Aix-Marsille Université, IRD, IHU Mediterranee Infection, 19-21 Blvd, Jean Moulin, 13005 Marseille, France; email: michel.drancourt@univ-amu.fr

\section{Increasing Virulence in Leprosy Indicated by Global Mycobacterium spp.}

\author{
William Levis, Tina Rendini, Frank Martiniuk
}

Author affiliations: Bellevue Hospital Center, New York, New York, USA (W. Levis, T. Rendini); JME Group, Roseland, New Jersey, USA (F. Martiniuk)

DOI: https://doi.org/10.3201/eid2401.171785

To the Editor: The November 2017 issue of Emerging Infectious Diseases had 3 articles about leprosy, including these topics: a United States-born patient who tested positive for Mycobacterium lepromatosis (1); a lethal case of Mycobacterium leprae manifested as Lucio's phenomenon in Peru (2); and pointing out that leprosy is an emerging disease in the eastern United States, including autochthonous cases without exposure to armadillos (3), which were previously shown to be a zoonotic source of transmission in the United States (4). Not only is leprosy not disappearing in the United States and globally, but the signs are pointing to a more virulent mycobacterial infection that is likely to be a microbial adaptation to the global use of multidrug therapy, as previously reported (5).

Lucio's phenomenon is fortunately rare; there is no proven effective therapy for this type 3 reaction in leprosy patients. Historically, Lucio's phenomenon was confined to Mexico, mostly in cases of diffuse lepromatous leprosy, also referred to as "Leprosy bonita." In recent years, it has 
been discovered elsewhere, including the first known case in India in 2001 (6). Two additional cases of lethal Lucio's leprosy were reported in 2 immigrants from Singapore to the United States, who were shown to have M. lepromatosis and M. leprae (7). The report of Levis et al. is likely confirmed by the recent discovery of $M$. lepromatosis and Lucio's outside of Mexico (5).

In summary, leprosy is an emerging infection in the United States, including autochthonous cases in the eastern United States. The reports in the November issue of Emerging Infectious Diseases of autochthonous M. lepromatosis and a lethal case of Lucio's phenomenon outside Mexico are ominous signs of a more virulent form of emerging leprosy.

\section{References}

1. Virk A, Pritt B, Patel R, Uhl JR, Bezalel SA, Gibson LE, et al. Mycobacterium lepromatosis lepromatous leprosy in US citizen who traveled to disease-endemic areas. Emerg Infect Dis. 2017;23:1864-6. http://dx.doi.org/10.3201/ eid2311.171104
2. Ramal C, Casapia M, Marin J, Celis JC, Baldeon J, Vilcarromero S, et al. Diffuse multibacillary leprosy of Lucio and Latapí with Lucio's phenomenon, Peru. Emerg Infect Dis. 2017;23:1929-30. http://dx.doi.org/10.3201/eid2311.171228

3. Rendini T, Levis W. Autochthonous leprosy without armadillo exposure, eastern United States. Emerg Infect Dis. 2017;23:1928. http://dx.doi.org/10.3201/eid2311.171145

4. Sharma R, Singh P, Loughry WJ, Lockhart JM, Inman WB, Duthie MS, et al. Zoonotic leprosy in the southeastern United States. Emerg Infect Dis. 2015;21(12):2127-2134. http://dx.doi.org/10.3201/eid2112.150501

5. Levis WR, Zhang S, Martiniuk F. Mycobacterium lepromatosis: emerging strain or species? J Drugs Dermatol. 2012;11:168-72. https://www.researchgate.net/publication/221688593_Mycobacterium_lepromatosis_Emerging_Strain_or_Species

6. Saoji V, Salodkar A. Lucio leprosy with Lucio phenomenon. Indian J Lepr. 2001 Jul-Sep.;73:267-72.

7. Han XY, Sizer KC, Tan H. Identification of the leprosy agent Mycobacterium lepromatosis in Singapore. J Drugs Dermatol. 2012;11:168-72.http://jddonline.com/articles/dermatology/ $\mathrm{S} 1545961612 \mathrm{P} 0168 \mathrm{X} / 1$

Address for correspondence: William Levis, New York Hansen's Disease Program, Bellevue Hospital Center, 462 1st Ave, Rm 17N7, New York, NY 10016, USA; email: doctorwilliamlevis@gmail.com

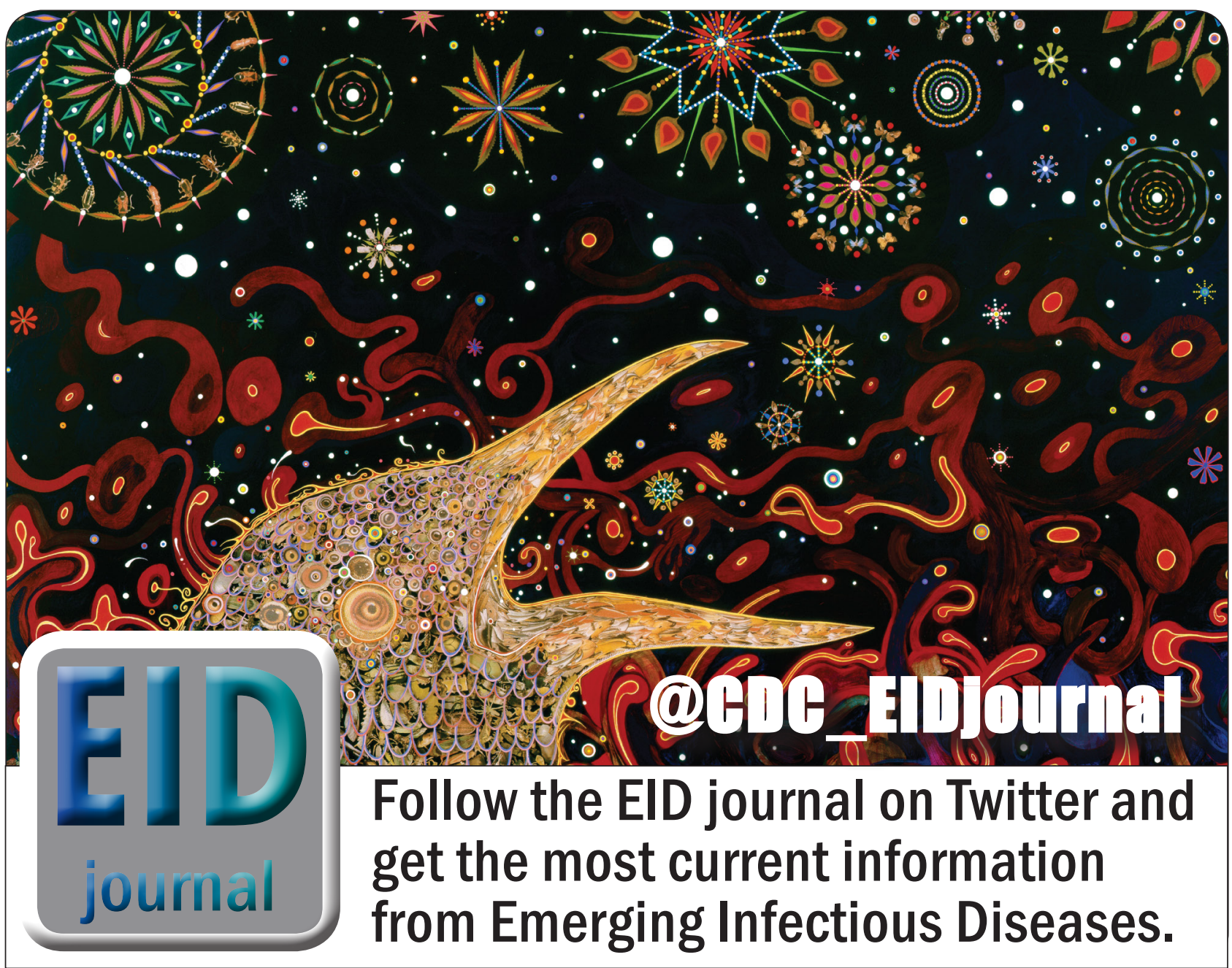

